\title{
The Impact of Circular Economy Development on China's Industrial Management In The Age of Information
}

\author{
Bihan ZHOU \\ Wuhan University of Technology, China
}

\begin{abstract}
Since the 1990s, circular economy has appeared in China and has gradually developed and grown. In recent years, with the development of information and the popularization of big data applications, circular economy has become the mainstream economic growth model China pursued. The concept of circular economy has also had a profound impact on China's corporate management. This article introduces the history of the development of human economy and the connotation of circular economy as well as the development history and development model of China's circular economy. It also discusses the impact of circular economy development on the management concepts and management methods of China's agricultural and industrial enterprises in the age of information.
\end{abstract}

\section{The history of economic development and the connotation of circular economy}

Throughout history, human economic development has experienced three modes. Starting with the traditional model, a one-way linear open economic process, which is extensive, poor efficiency as well as low added value, and then transitions to the "end-of-process governance model", meaning treatment after pollution. However, this economic development mode still does great harm to the environment as it failed to prevent pollution from the source.

In the 1960s, the idea of "circular economy" was formed in the United States and appeared in China in the 1990s. With the revalence of the concept of green and low-carbon development, circular economy has become a high-quality economic growth mode pursued in all fields of society currently. Circular economy, literally, is a closed-loop economic growing mode, Under circular economy, human production activities follow the recycling model of "resources-products-renewable resources", which conforms to the concept of sustainable development and replaces the traditional one-way flow linear economic model. The circular economy follows the principle of reduction, reuse and recycling, aiming to reduce the flow of materials and energy used in human production and consumption activities and improve resource utilization efficiency as much as possible.

\section{The development history and development model of China's circular economy}

"Circular economy" sprouted in China at the beginning of the 20th century. Liu Qingshan first used the term "circular economy" in 1994. Prior to this, China had always adopted a resource-oriented one-way traditional economic model and an end-of-process governance model . At the end of the 20th century, as environmental problems became increasingly prominent, China learned experience from developed countries such as Germany and Japan, who are the leaders and models of circular economy development, and adopted low-energy consumed clean production methods. On July 28, 2003, $\mathrm{Hu}$ Jintao, General Secretary of the CPC Central Committee, carried out "Adhere to people-oriented, establish a comprehensive, coordinated and sustainable development concept, and promote the all-round development of economy, society and people." Since then, circular economy has become a new economic growth model that China is pursuing.

Take renewable resources as an example, as an important part of the circular economy, China's total renewable resources have grown steadily from 2013 to 2018 (up to $38.23 \%$ in 6 years), and the comprehensive utilization of waste resources has achieved rapid growth during this period. Development, although the Ministry of Commerce has not released the exact data for 2019, the market generally predicts that China's recycling of renewable resources will exceed 340 million tons in 2019, and will exceed 350 million tons in 2020, reaching and exceeding the target set by relevant state departments in 2017. (Note: In 2017, the Ministry of Industry and 
Information Technology, the Ministry of Commerce, and the Ministry of Science and Technology recently issued a document to promote the development of the renewable resource industry, proposing that by 2020 , the amount of renewable resources recycled will reach 350 million tons.) From this, we can see the development prospects of China's circular economy and The development potential is very broad.

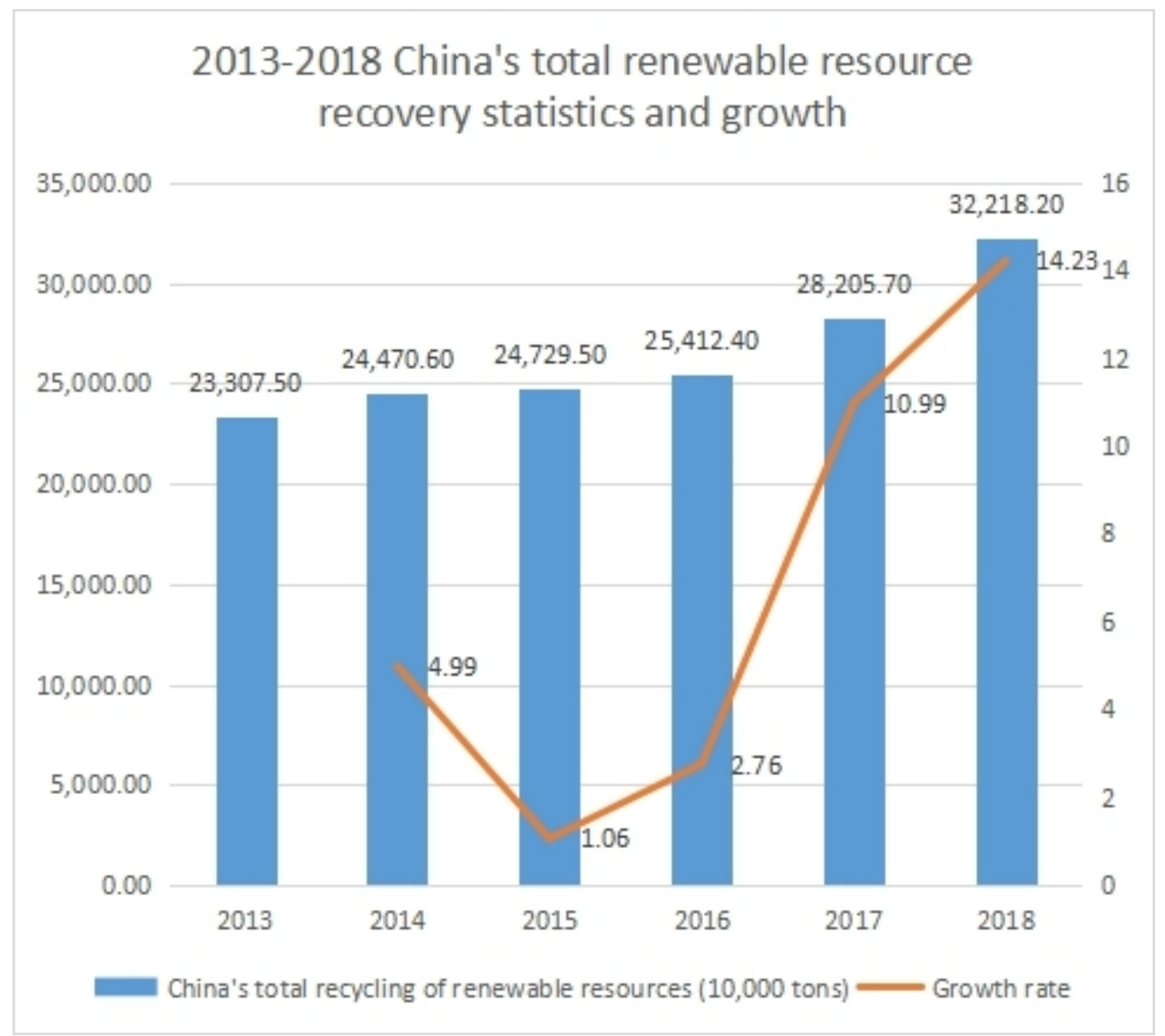

Fig 1. 2013-2018 China's total renewable resource recovery statistics and growth

The development model of circular economy is divided into industrial development model and regional development model. The industrial development model emphasizes on the areas of production and consumption, as well as the industries of eco-industry, eco-agriculture, green service industry, waste recycling, recycling and harmless disposal industries. The regional development model of circular economy refers to the effective combination of circular economy and regional sustainable development. It is built on the basis of regional economic development. While ensuring the compliance with the laws of regional development, it is based on the principles of natural ecological cycles to construct a reasonable industrial structure and Regional consumption system. It also focus on the efficient use of resources to promote social and economic development.

\section{The impact of the development of circular economy on China's industrial management in the age of information}

\subsection{Agriculture}

As an important part of sustainable development, the development of agricultural circular economy is an indispensable and crucial step for the comprehensive construction of circular economy and the establishment of the entire circular society. The gradual popularization and maturity of the concept of circular economy has also promoted the transformation of the management method of China's agricultural industry.

In response to Zhu Zhaoliang, an academician of the Chinese Academy of Sciences who carried out the two basic ideas of "transformation" for the development of the agricultural economy, which are "using the operation law of circular economy to prevent and control agricultural point source and non-point source pollution" and "using agricultural circular economy to turn the development of traditional agriculture into industrial agriculture, and to turn resource-consuming agriculture into resource recycling agriculture". The management concept of China's agricultural industry has been changed and improved in terms of innovative organizational forms, sound service systems, active publicity and promotion, as well as strengthening of overall coordination. In terms of organizational forms, different new agricultural business entities carry out various forms of cooperation to jointly promote green governance, play a demonstrative role, improve resource utilization, and achieve large-scale benefits. They also use modern information technology such as the Internet to promote the popularization of agricultural circular economy information. Various agricultural industrial enterprises have increased their 
efforts to publicize circular economy, popularize the basic concepts of circular economy, and actively carry out publicity and education activities of agricultural circular economy as well as innovate publicity methods . Finally, all levels agricultural industry departments must strictly abide the relevant national plans and opinions, clarify the division of labor and strengthen the coordination of different departments under the premise of combining with the actual situation as well as improve the performance evaluation system.

\subsection{Industry[1][2]}

During the process of traditional linear model of economic development, the extensive resource management and inefficient use of resources in industrial industries have caused serious pollution to the environment. Therefore, the industrial industry has determined to reform and has played an extremely important role in circular economy. The transformation of its management methods is a booster for the development of circular economy.

In the general environment of the development of circular economy concept, the management style reform of the industrial industry can be divided into the change of management concept and the development of management mode. In order to maximize the efficiency of resource utilization, the modern industrial industry regards minimizing investment and maximizing utilization as the new management concept of industrial production. During the production process, it protects the ecological environment, realizes clean production, and builds an ecological enterprise. The economic, social and ecological benefits are unified. In terms of management mode, the industrial industry focuses on comprehensive utilization of resources and optimizing the industrial chain. While building a green industrial chain, advanced science and technology and environmentally friendly production methods are used to extend the industrial chain, improve the comprehensive utilization of resources, and make the industry diversified.

\subsection{Modern commercial industry[3][4]}

Under the influence of the circular economy, the management concepts and management methods of the modern commercial industry have also undergone changes. First of all, it is necessary to establish a green management concept, and include the environmental impact of commodity production and operation activities into the corporate performance evaluation indicators. Pay attention to the management and development of human resources, from a single technology management to information, knowledge, innovation, talent and other diversified corporate management.

Secondly, product packaging, circulation, and recycling are important components of commercial industry production and operation activities. Products should be packaged in a recyclable way and sustainable development indicators such as easy recycling, degradability, and ecological protection should be used as
Important indicators to measure products standards . In the process of commodity circulation, promote the development of advanced technology, and use emerging science and technology to ensure the greening of commodity transportation are necessary.

In addition, the overall industrial profit of China's development of comprehensive waste resource utilization has an overall upward trend from 2015 to 2019. In terms of state support, industrial development and the statistical data below, the profit prospects of enterprises in the development of circular economy are promising, which has stimulated more Industries and enterprises to transform into a circular economy development model.

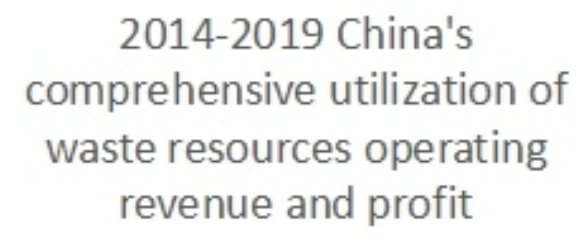

$6000 \longrightarrow 300$

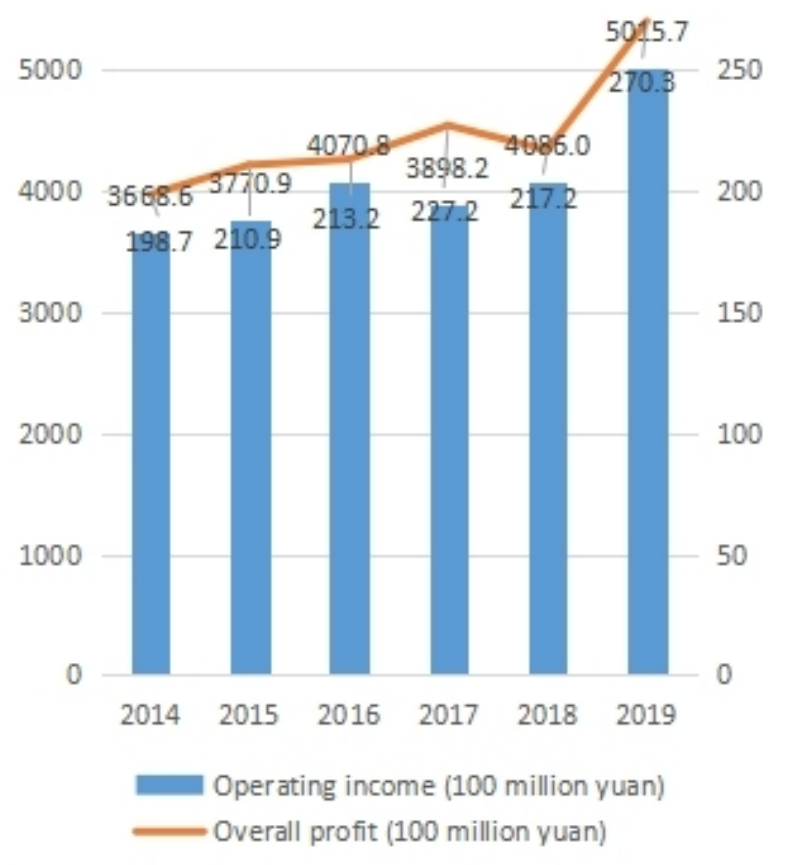

Fig 2. 2014-2019 China's comprehensive utilization of waste resources operating revenue and profit

Besides, the state has also issued a series of policies to support the development of China's circular economy.

In 2007, the 17th National Congress of the Communist Party of China raised the circular economy to the height of the national strategy for the first time.

In 2008, the National People's Congress promulgated and implemented the "Recycling Economy Promotion Law of the People's Republic of China"

In 2013, the State Council issued the "Circular Economy Development Strategy and Immediate Action Plan" In 2017, 14 departments including the National Development and Reform Commission and the Ministry of Science and Technology jointly issued the "Leading Action for Circular Development"[5] 


\section{Conclusion}

In summary, as the mainstream economic development concept of current society, circular economy has had a significant impact on management concepts and management methods of various industries in China. All industries are pursuing a low-input and high-output production efficiency, establishing a "resources Products-renewable resources-renewable products" closed-loop production model. They also actively establish green development concepts and development strategies, promote the progress of emerging science and technology and combine science and technology with circular economy development concepts, using them to innovate industrial management models.

\section{References}

1. Huihua Ling. Production management reform of industrial enterprises under the environment of circular economy $[\mathrm{J}]$. Business Times,( 2008), 000(017): 58-59.

2. Yongjian Liu. Discussion on the management of circular economy industrial enterprises in the information age $[\mathrm{J}]$. Building Materials and Decoration,( 2013(10)):183-184.

3. Jieyu Zhang. Discussion on the development strategy of enterprise informatization under the theory of circular economy $[\mathrm{J}]$. China Collective Economy, (2020).

4. Chong Liu, Lianshui Li . The transformation of business management concepts in circular economy [J]. Modern Management Science, (2004).

5. https://www.sohu.com/a/393080051_99952368 